\title{
Morphemic and Semantic Analyses Skills of Senior High School Students
}

\author{
Gianfranco U. Ubamos \\ Mabini National High School, Escalante City, Philippines \\ gianfranco.ubamos@deped.gov.ph \\ http://orcid.org/0000-0003-3065-4024
}

Ivy G. Aboy

University of Negros Occidental-Recoletos, Bacolod City, Philippines

ivygonzales_aboy@yahoo.com

\begin{abstract}
Few studies focus on measuring the morphemic and semantic analyses skills of learners. Thus, this descriptive-comparative study aimed to find out the level of morphemic and semantic analyses skills and if a significant difference exists in the levels of morphemic and semantic analyses skills of 359 senior high school students as a whole and grouped according to grade level, track, and sex. Results showed low morphemic and average semantic analyses skills, a non-significant difference in both morphemic and semantic analyses skills when students were grouped according to grade, but a significant difference in both skills when grouped by track and sex. Despite the students' better semantic analysis than morphemic analysis skills, they still need heavy to light intervention and enhancement to develop their skills further. Thus, a vocabulary building module was designed for the senior high school students.
\end{abstract}

Keywords: Language Education, Morphemic Analysis Skills, Semantic Analysis Skills, Descriptive-Comparative Design, Philippines

Date Submitted: June 8, 2019

Date Revised: December 17, 2019

Date Accepted: December 29, 2019

\subsection{Introduction}

The current K-12 Basic Education Curriculum (2013 \& 2016) of the Department of Education emphasizes the morphemic analysis and semantic analyses skills among learners. Thus, as early as elementary, background knowledge of word parts is introduced. At the intermediate level, the children are familiarized with contextual clues. Through the "spherical" approach to learning, learners are guided from the basic concepts of both morphemic and semantic analyses to more complex forms of 
application. Emphasis on these skills is justified, for they empower learners to be less dependent on reference materials when they are reading.

A morpheme is the smallest unit of language with meaning (McGregor, 2009; Akmajian, Farmer, Bickmore, Demers, \& Harnish, 2017). Thus, morphemic analysis means distinguishing the word parts to arrive at an inferred meaning of a given unfamiliar word (Diamon \& Gutlohn, 2006). The prefixes, suffixes, root words, or any affix,may help reveal information regarding the word as a whole. Linguists assert that morphemic analysis is a powerful tool for students' word recognition in vocabulary acquisition (Kieffer \&Lesaux, 2007; Varatharajoo, Asmawi, Rengasamy, Sukumaran, Sia Seng Lee, Raju, \& Ahmad,2014) and a reliable predictor of students' reading achievement (Guo, Roehrig, \& Williams, 2011).

On the other hand, semantics is an "investigation of sentence meaning - and the meanings of various signs making up sentences," (Mcgregor, 2009, p. 133). Thus, semantic analysis, or contextual analysis, uses the details of the surrounding information or the context to guess the meaning of a word (Baumann, Font, Tereshinski, \&Olejnik, 2002; Royce Adams, \& Patterson, 2005). Experts suggest that because semantic analysis skill is very acquirable, students should be aware of the various clues available to them (Greenwood \& Flanigan, 2007; Wilson, 2013).

However, despite the explicit teaching of multiple competencies that focus on developing the morphemic and semantic analyses skills of the learners, the Philippines has been labeled a "nation of non-readers" (Luz, 2007). Considering the relationship between vocabulary and reading comprehension, educators should take steps to understand better the current state of the vocabulary skills of Filipino learners to cope with the needs and gaps.

Locally, senior high school teachers have observed a decline in the performance of the learners in English related subjects, especially in lessons involving complex words. The learners struggle in comprehending texts and even in recognizing words. Thus, with the emphasis on both skills during the learners' elementary and junior high school levels, teachers must necessarily exert effort in gathering data regarding the level of mastery of the students.

Nevertheless, most related literature and studies currently existing focus on checking the vocabulary knowledge and not vocabulary skills. Some deal with measuring and analyzing vocabulary knowledge, relationships between vocabulary and L2 proficiency, and selective vocabulary knowledge (Bogaards \& Laufer, 2004; Masrai \& Milton, 2012). However, few studies have measured the morphemic and semantic analyses skills of learners. Also, the newly established senior high school selected for this study lacks data regarding the vocabulary skills of its learners.

Hence, this study determined the level of use of morphemic analysis skills in the areas of Prefix + Root Word, Root Word + Suffix, and Prefix + Root Word + Suffix and the level of semantic analysis skills in the areas of synonyms, antonyms, definition, and restatement among senior high school students of the selected national high school when they are taken as a whole or when grouped according to grade level, track, and sex. This study also sought the differences in the morphemic and semantic analysis skills of the senior high school students when they are grouped according to sex, track, and grade level. 
The findings of this study were utilized as the basis for crafting a vocabulary building module designed to develop the morphemic and semantic analysis skills of the senior high school students of the selected national high school.

\subsection{Framework of the Study}

This study assumes that when students encounter unfamiliar words, they use the strategies and skills that they have learned during the early years of their education. In this context, this study is mainly anchored on two theories: Vygotsky's Constructivism and Kant's Schema Theory.

Through child-centered teaching that exposes learners to insights in a stepby-step manner, and via the guidance of a teacher, learning is achieved. This approach embodies the educational implications of Constructivism wherein learning through gradual exposure to valuable competencies equips learners with the necessary skills for lifelong learning. Using the same spherical approach, learners are guided through a solid foundation of what is learned before introducing more complex insights. This approach also showcases the use of schema as the storage facility of the brain wherein previous knowledge is kept and used when making sense of newly encountered learning.

Specifically, Vygotskyan's sociocultural theories (Vygotsky, 1978, 1986; Flowerdew, 2012) hold that knowledge is co-constructed by experiences that allow one to have exchanges with others, such as dialogue and negotiation. Through guided practice like "scaffolding," teachers can expose students to concepts, including learning vocabulary learning strategies such as morphemic and semantic analyses skills.

Additionally, this study assumes that man learns new items introduced to him through connection with his previous knowledge, or schema, a structure in semantic memory that specifies the expected sequence of events (Rumelhart, 1980). Therefore, to enable one to create meaning or sense, one must be able to connect his/her new items to his/her background knowledge.

Moreover, this study contends that the students' demographic characteristics could make a difference in their level of vocabulary skills. Experts have insisted that both morphemic and semantic analyses skills play a significant role in the comprehension of the learners (Boonkongsaen, 2013). However, in the current study, both skills are measured as they are or as existing skills of the learner assuming that, ideally, the learners have already been exposed to these skills as early as elementary up to junior high school. The test questionnaire, therefore, consists of items unfamiliar to the participants to ensure that they would turn to the use of morphemic or semantic analyses skills for deducing meaning (Behlol \& Kaini, 2011). Items for morphemic analysis skills were isolated words to highlight the use of prefix, root words, suffix as main clues to infer meaning (Kieffer \&Lesaux, 2007, cited in Varatharajoo et al., 2015)while items for semantic analysis skills used unfamiliar words integrated into the sentences that contain clues such as synonym, antonym, restatement, and definition used as contextual clues to suggest the meaning of the unknown word (Easterbrook, 2013). Though these two skills are often used together (Wang, 2011), the current study focuses on isolating, as much as possible, both skills to see which skills are more mastered by the learners and which skills need intervention. 
Basically, variables have been explored as possible indicators of learners' vocabulary such as the differences in the competencies per grade level of the curriculum guide of the K-12 curriculum. Wanpen, Sonkoontodb, \& Nonkukhetkhong (2012) highlighted vocational education in relation to vocabulary, and Llach and Gallego (2012) highlighted sex and vocabulary. The output is a vocabulary development module which focuses on the given variables as the basis for giving instruction, activities, and evaluation for current and incoming senior high school students.

\subsection{Methods}

The researcher-made test questionnaire consists of three parts: the personal profile of the 359 senior high school students, the 15-item test on morphemic analysis; and, the 20-item test on semantic analysis. Using Carter V. Good and Douglas E. Scates's criteria, three experts' evaluation of the content and face validity of the instrument yielded an average of 3.89 out of 4 . Reliability was established through a dry run among 30 students from another national high school, and item analysis to ensure internal consistency. The calculation using Cronbach's Alpha yielded a reliability index of 0.833 , indicating that it is reliable.

In gathering the data, the researcher sought the approval of the Schools Division Office and the school principal to conduct the study and scheduled the test administration. Before the test administration, the researcher had oriented the English teachers regarding the study and its objectives and requested them to assist in the test administration that took place for three days during their English classes.

During the test administration, the researcher explained the nature of the study, assured the respondents of the confidentiality of their identity and responses, and gave them instructions. Furthermore, the researcher assisted them in accomplishing Part 1 of the questionnaire and gave them 60 minutes to answer the test. The questionnaires were retrieved after the time allotted for the test.

Adherent to the research ethics protocol, the researcher asked for the informed consent of the respondents, ensured confidentiality of the personal information and responses of the students, and ensured proper storage of the questionnaires until after oral presentation and publication when they will be properly disposed of.

Data were analyzed using appropriate statistical tools. Statistical Package for Social Sciences (SPSS) and Microsoft Excel were utilized were used to process the data. Morphemic and semantic analyses skills of the senior high school as a whole and according to track, sex, and grade level were analyzed descriptively using the mean and standard deviation. Differences in the morphemic and semantic analysis skills of the learners by track, sex, and grade level were analyzed through comparative analysis using the T-test.

\subsection{Results and Discussion}

\section{Level of Morphemic Analysis Skills}

Table $1 \mathrm{~A}$ and $1 \mathrm{~B}$ show that when taken as a whole, the level of morphemic analysis skills was low. All areas were low, although the area Prefix +Root Word + Suffix structure got the highest mean score, and the Root Word +Suffix got the lowest. This 
low performance means that the students displayed unsatisfactory morphemic analysis skills. They appeared to have an underdeveloped ability to break down the parts of the words and infer meaning, revealing that they displayed the schema of morphemic analysis skills, yet they were unable to put the skill/s to use. This likewise suggests their difficulty in identifying the meaningful parts of the words, i.e., prefixes, suffixes, and roots. Without enough morphological awareness, they would find difficulty in deciphering the smallest meaningful unit in a word (morpheme) to arrive at the correct meaning of an unfamiliar word (Carlisle, 2010; Karimi, 2012; Oz, 2014). Hence, they need heavy or extensive intervention.

Similarly, when grouped according to grade level, the level of morphemic analysis skills of both Grade 11 and Grade 12 was low. In all subcategories, Prefix+ Root Word, Root Word+ Suffix, and Prefix+ Root Word + Suffix, they are also consistently low, indicating unsatisfactory skills of both grades.

When grouped according to track, the morphemic analysis skills of students in the academic track were average as a whole, although they were low in the Prefix+ Root Word and Root Word+ Suffix. They outperformed the TVL students who scored low as a whole and in all areas.

These reveal that students belonging to the academic track exhibited a satisfactory level of mastery, albeit they need specific interventions. The learners' level of mastery in using morphemic analysis skills is observable. However, they are not yet ready for complex items, and they have not yet achieved independent use of the skills; thus, they need specific intervention. Oppositely, the TVL track students exhibited a schema of the skills but displayed unsatisfactory skills. The consistency of the results suggests that they require heavy intervention to develop the skills.

It appears that the students' choice of the track reflects the type of career they wish to pursue after senior high school or college education. Based on the current ( $\mathrm{K}$ to 12) curriculum, those who chose the academic track have plans of proceeding to college while those enrolled in TVL opt to work or open a business. Hence, this particular variable can be somehow associated with the motivation and interest of the students. Although this study does not directly consider these aspects, they are important concepts that may clarify the context of the results. In relation to these concepts, motivation has a very important role in the vocabulary development of vocational learners because there is a high correlation between vocabulary learning beliefs and vocabulary learning strategies (Masrai \& Milton, 2012). Without such motivation, vocational learners tend to exhibit low interest in learning vocabulary.

Lastly, the analysis revealed that when grouped according to sex, the low levels of morphemic analysis skills do not seem to separate the performance of the males from the females in all subcategories. Both groups performed unsatisfactorily in morphemic analysis skills, showing that they displayed the schema of morphemic/ semantic analysis skills but were unable to put the skills to effective use. Thus, they need extensive intervention.

The findings are contrary to the results of Zoghi \& Malmeer (2013), where females outperformed males in all aspects of language learn in all aspects of language learning. 
Table 1A. Level of Morphemic Analysis Skills

\begin{tabular}{|c|c|c|c|c|c|c|}
\hline \multirow[t]{2}{*}{ Variable } & \multicolumn{3}{|c|}{$\begin{array}{c}\text { Prefix + } \\
\text { Root Word }\end{array}$} & \multicolumn{3}{|c|}{$\begin{array}{l}\text { Root Word + } \\
\text { Suffix }\end{array}$} \\
\hline & M & SD & Int & M & SD & Int \\
\hline \multicolumn{7}{|l|}{ Grade Level } \\
\hline Grade $11(n=203)$ & 1.42 & 1.12 & Low & 1.40 & 1.19 & Low \\
\hline Grade $12(n=156)$ & 1.71 & 1.16 & Low & 1.60 & 1.14 & Low \\
\hline \multicolumn{7}{|l|}{ Track } \\
\hline Academic ( $n=139)$ & 1.95 & 1.09 & Low & 1.86 & 1.29 & Lo \\
\hline TVL $(n=220)$ & 1.30 & 1.11 & Low & 1.25 & 1.03 & Low \\
\hline \multicolumn{7}{|l|}{ Sex } \\
\hline Male $(n=176)$ & 1.37 & 1.18 & Low & 1.38 & 1.14 & Low \\
\hline Female $(n=183)$ & 1.72 & 1.09 & Low & 1.60 & 1.19 & Low \\
\hline As a Whole $(n=359)$ & 1.55 & 1.14 & Low & 1.49 & 1.17 & Low \\
\hline
\end{tabular}

Table 1B. Level of Morphemic Analysis Skills

\begin{tabular}{|c|c|c|c|c|c|c|}
\hline \multirow[t]{2}{*}{ Variable } & \multicolumn{3}{|c|}{$\begin{array}{l}\text { Prefix+ Root Word } \\
+ \text { + Suffix }\end{array}$} & \multicolumn{3}{|c|}{$\begin{array}{l}\text { Morphemic Analysis } \\
\text { Skills }\end{array}$} \\
\hline & M & SD & Int & M & SD & Int \\
\hline \multicolumn{7}{|l|}{ Grade Level } \\
\hline Grade $11(n=203)$ & 1.70 & 1.22 & Low & 4.53 & 2.63 & Low \\
\hline Grade $12(n=156)$ & 1.64 & 1.26 & Low & 4.95 & 2.79 & Low \\
\hline \multicolumn{7}{|l|}{ Track } \\
\hline Academic $(n=139)$ & 2.34 & 1.32 & Average & 6.14 & 2.90 & Average \\
\hline TVL $(n=220)$ & 1.26 & 0.98 & Low & 3.81 & 2.13 & Low \\
\hline \multicolumn{7}{|l|}{ Sex } \\
\hline Male $(n=176)$ & 1.54 & 1.26 & Low & 4.28 & 2.65 & Low \\
\hline Female $(n=183)$ & 1.81 & 1.21 & Low & 5.13 & 2.70 & Low \\
\hline As a Whole ( $n=359)$ & 1.68 & 1.24 & Low & 4.71 & 2.70 & Low \\
\hline
\end{tabular}

\section{Level of Semantic Analysis Skills}

Table 2 shows that when taken as a whole, the level of semantic analysis skills was average. Definition clues had the highest mean score, which is interpreted as an average level while restatement clues garnered the lowest score, which is interpreted as low.

The average results for synonym, antonym, and definition clues mean satisfactory skills illustrated by observable background knowledge and ability to utilize the skill at the basic level. However, they have not yet achieved independent use of the skill, so they are not ready for complex items. Therefore, they still need specific but light to moderate interventions to ensure full mastery in these areas.

In contrast, the low result of restatement clues implies that they possess poor background knowledge and skills. Accordingly, heavy intervention in the use of restatement clues is needed to develop it as a meaning-inferring skill. Data suggest that in both areas, students tend to display only less or enough skills but not total mastery nor independent use of the skill, thus, indicating the need for specific or light to heavy 
intervention. The results mirror the statements of experts who agree that learners learn words from context (Nagy, Anderson, \& Herman,1987; Kile, 2013; Brusnighan, 2015).

When grouped according to grade level, the semantic analysis skills of the grade 11 was low while that of grade 12 was average. As a whole and per subcategory, the grade 12 displayed better performance compared to grade 11 , the former illustrating a slight advantage of the semantic analysis skills over the latter. The Grade 12 students' semantic analysis skills were average or satisfactory. These imply that the learners' level of mastery in using semantic analysis skills is observable, but they are not yet ready for advance items. Their independent use of the skill/s is not achieved. In contrast, the grade 11 group demonstrated an unsatisfactory level of semantic analysis skills in restatement and synonyms, displaying the schema of semantic analysis skills but were unable to effectively and independently use the skills.

The higher overall performance of Grade 12 compared to Grade 11 reflects the statement that learning vocabulary is natural, and it grows naturally and almost effortlessly as long as the learner encounters words in context (Jose, 2015). He further explained that children in school encounter words through their reading. As students spend more time in school, they are more likely to learn more vocabulary words, hence, allowing learning to be facilitated by the increase in the learner's grade level.

Furthermore, with regards to the track, the students under the academic track had an average level of semantic analysis skills in restatement clues, synonym clues, antonym clues, and definition clues. The TVL track students showed consistently low semantic analysis skills in all four areas.

Table 2A. Level of Semantic Analysis Skills

\begin{tabular}{|c|c|c|c|c|c|c|c|c|c|}
\hline \multirow{2}{*}{ Variable } & \multicolumn{3}{|c|}{ Restatement } & \multicolumn{3}{|c|}{ Synonym } & \multicolumn{3}{|c|}{ Antonym } \\
\hline & $\mathbf{M}$ & SD & Int & $\mathbf{M}$ & SD & Int & M & SD & Int \\
\hline \multicolumn{10}{|l|}{ Grade Level } \\
\hline Grade $11(n=203)$ & 1.72 & 1.35 & Lo & 1.98 & 1.19 & Lo & 2.14 & 1.30 & Av \\
\hline Grade $12(n=156)$ & 2.00 & 1.42 & Lo & 2.10 & 1.15 & $\mathrm{Av}$ & 2.20 & 1.38 & Av \\
\hline \multicolumn{10}{|l|}{ Track } \\
\hline Academic (n=139) & 2.42 & 1.41 & $\mathrm{Av}$ & 2.36 & 1.23 & $\mathrm{Av}$ & 2.74 & 1.41 & Av \\
\hline TVL $(n=220)$ & 1.48 & 1.24 & Lo & 1.82 & 1.09 & Lo & 1.80 & 1.16 & Lo \\
\hline \multicolumn{10}{|l|}{ Sex } \\
\hline Male $(n=176)$ & 1.57 & 1.30 & Lo & 1.94 & 1.11 & Lo & 1.95 & 1.30 & Lo \\
\hline Female $(n=183)$ & 2.10 & 1.42 & Av & 2.12 & 1.22 & $\mathrm{Av}$ & 2.37 & 1.35 & Av \\
\hline As a Whole $(n=359)$ & 1.84 & 1.39 & Lo & 2.03 & 1.17 & $A v$ & 2.17 & 1.34 & $A v$ \\
\hline
\end{tabular}

These findings show that the academic track students' semantic analysis skills are satisfactory. Their level of mastery in using semantic analysis skills is observable, but they are not yet ready for more advanced items. They also displayed a lack of independent use of the skills. Thus, specific interventions may be needed. The TVL group, however, showed unsatisfactory semantic analysis skills. Their level is low, and they require heavy intervention. The academic track requires light intervention in the semantic analysis as a whole and in all its subcategories while the TVL track needs heavy intervention in the semantic analysis as a whole and all its subcategories. 
Table 2B. Level of Semantic Analysis Skills

\begin{tabular}{|c|c|c|c|c|c|c|}
\hline \multirow{2}{*}{ Variable } & \multicolumn{2}{|c|}{ Definition } & \multirow[b]{2}{*}{ Int } & \multicolumn{3}{|c|}{ Semantic Analysis Skills } \\
\hline & M & SD & & M & SD & Int \\
\hline \multicolumn{7}{|l|}{ Grade Level } \\
\hline Grade 11 (n=203) & 2.15 & 1.10 & $A v$ & 7.99 & 3.39 & Lo \\
\hline Grade $12(n=156)$ & 2.31 & 1.16 & $A v$ & 8.61 & 3.70 & $A v$ \\
\hline \multicolumn{7}{|l|}{ Track } \\
\hline Academic ( $n=139)$ & 2.56 & 1.21 & $A v$ & 10.08 & 3.69 & $A v$ \\
\hline TVL $(n=220)$ & 2.00 & 1.01 & Lo & 7.10 & 2.91 & Lo \\
\hline \multicolumn{7}{|l|}{ Sex } \\
\hline Male $(n=176)$ & 2.00 & 1.13 & Lo & 7.46 & 3.34 & Lo \\
\hline Female $(n=183)$ & 2.43 & 1.09 & $A v$ & 9.02 & 3.56 & $A v$ \\
\hline As a Whole $(n=359)$ & 2.22 & 1.12 & $A v$ & 8.26 & 3.54 & $A v$ \\
\hline
\end{tabular}

Academic track students tend to perform better than their TVL counterparts because they are more likely to be exposed to reading materials and more opportunities to practice their skills. Studies have shown that interest (Shakouri, N., Behdani, R., \& Teimourtash, 2017) and incidental learning (Laufer \& Hulstijn, 2001) are factors in developing better vocabulary skills.

Alternatively, the male students garnered a low score as a whole while the female students earned an average level of semantic analysis skills. These findings reveal that the male group's semantic analysis skills are unsatisfactory for semantic analysis as a whole and in all its subcategories. They displayed a schema of semantic analysis skills but were unable to use them successfully. They need heavy intervention. The female learners' semantic analysis skills are satisfactory, illustrating a notable level of skill in using semantic analysis skills, but may lack mastery. Hence, they are not yet ready for more complex items. They have not yet achieved independent use of the skills. Thus, they may need specific intervention to reach the level at which they can use the skills with a high degree of independence.

\section{Difference in the Morphemic Analysis Skills}

Table 3A shows no significant difference in the level of morphemic analysis skills of the senior high school students when they are grouped according to grade level. Per subcategory, Prefix + Root Word showed a significant difference. Oppositely, Suffix + Root Word and Prefix + Root Word + Suffix also did not show any statistical difference.

This result means that the level of the morphemic analysis skills of the senior high school students is statistically the same for both Grades 11 and 12 . With this result, it is clear that the difference between the respondents' grade level does not necessarily affect their morphemic analysis skills. Grade 11 and grade 12 students share the same use of morphemic analysis as a tool for inferring meaning.

Nevertheless, morphemic analysis is influenced by several factors. Bangs and Binder (2016) argued that learners introduced to morphological awareness tend to demonstrate better vocabulary performance compared to those who were not. In the current case, however, both groups were expected to have sufficiently equal exposure to structural or morphemic analysis during their junior high school simply because both 
Table 3A. Difference in the Morphemic Analysis Skills by Grade Level

\begin{tabular}{llllll}
\hline \multirow{2}{*}{ Variable } & \multicolumn{2}{l}{ Grade Level } & $\mathrm{t}$ & $\mathrm{df}$ & $\mathrm{p}$ \\
& Grade 11 & Grade 12 & & & \\
\hline \multirow{2}{*}{ Prefix + Root Word } & 1.42 & 1.71 & 2.378 & 357 & 0.018 \\
& $(1.12)$ & $(1.16)$ & & & \\
\hline \multirow{2}{*}{ Root Word + Suffix } & 1.40 & 1.60 & 1.543 & 357 & 0.124 \\
& $(1.19)$ & $(1.14)$ & & & \\
\hline Prefix+ Root Word & 1.70 & 1.64 & 0.481 & 357 & 0.631 \\
+ Suffix & $(1.22)$ & $(1.26)$ & & & \\
\hline \multirow{2}{*}{ Morphemic Analysis Skills } & 4.53 & 4.95 & 1.451 & 357 & 0.148 \\
& $(2.63)$ & $(2.79)$ & & & \\
\hline
\end{tabular}

Note: *the difference in the means is significant when $\mathrm{p} \leq 0.05$

Table 3B. Difference in the Morphemic Analysis Skills by Track

\begin{tabular}{llllll}
\hline \multirow{2}{*}{ Variable } & $\begin{array}{l}\text { Track } \\
\text { Academic }\end{array}$ & TVL & & t & df \\
& 1.95 & 1.30 & $5.486^{*}$ & 357 & 0.000 \\
Prefix + Root Word & $(1.09)$ & $(1.11)$ & & & \\
\hline \multirow{2}{*}{ Root Word + Suffix } & 1.86 & 1.25 & $4.887^{*}$ & 357 & 0.000 \\
& $(1.29)$ & $(1.03)$ & & & \\
\hline Prefix+ Root Word & 2.34 & 1.26 & $8.877^{*}$ & 357 & 0.000 \\
+ Suffix & $(1.32)$ & $(0.98)$ & & & \\
\hline \multirow{2}{*}{ Morphemic Analysis Skills } & 6.14 & 3.81 & $8.783^{*}$ & 357 & 0.000 \\
& $(2.90)$ & $(2.13)$ & & & \\
\hline
\end{tabular}

Note: *the difference in the means is significant when $\mathrm{p} \leq 0.05$

Table 3C. Difference in the Morphemic Analysis Skills by Sex

\begin{tabular}{|c|c|c|c|c|c|}
\hline \multirow{2}{*}{ Variable } & \multicolumn{2}{|l|}{ Sex } & \multirow[t]{2}{*}{$t$} & \multirow[t]{2}{*}{ df } & \multirow[t]{2}{*}{ p } \\
\hline & Male & Female & & & \\
\hline \multirow{2}{*}{ Prefix + Root Word } & 1.37 & 1.72 & $2.944 *$ & 357 & 0.003 \\
\hline & $(1.18)$ & (1.09) & & & \\
\hline \multirow{2}{*}{ Root Word + Suffix } & 1.38 & 1.60 & 1.789 & 357 & 0.075 \\
\hline & $(1.14)$ & (1.19) & & & \\
\hline \multirow{2}{*}{$\begin{array}{l}\text { Prefix+ Root Word } \\
+ \text { Suffix }\end{array}$} & 1.54 & 1.81 & $2.068 *$ & 357 & 0.039 \\
\hline & $(1.26)$ & $(1.21)$ & & & \\
\hline \multirow{2}{*}{ Morphemic Analysis Skills } & 4.28 & 5.13 & $2.983^{*}$ & 357 & 0.003 \\
\hline & $(2.65)$ & $(2.70)$ & & & \\
\hline
\end{tabular}

Note: *the difference in the means is significant when $p \leq 0.05$

groups, ideally, have gone through the same subjects as specified by the respective curriculum guides from elementary to junior high school. Therefore, the difference between both groups when considering the grade level is not significant.

When grouped according to track, findings revealed a significant difference. These results mean that the morphemic analysis skills of senior high schools differ when they are grouped into academic and TVL track. In comparison to grade level and sex, only the tracks showed uniformed results both as a whole and per subcategory. 
Students who aim to focus on technical and vocational skills undergo English for Specific Purposes or English for Vocational Purposes. This variation of English is different from General English, which is in mainstream education. Learners who aim to develop academically may have higher English proficiency than those who opt to focus on skills development (Marwan, 2015).

\section{Difference in the Semantic Analysis Skills}

Table 4A shows a non-significant difference in the level of semantic analysis skills of the senior high school students when they are grouped according to grade level.

These findings challenge the assumption of linguists that learners learn a lot of words per year (Nagy, Perman, \& Anderson, 1985). Given the expected difference between age per grade level and the length of formal education, the Grade 12 participants are most likely to exhibit better vocabulary than their Grade 11 counterparts. Furthermore, Nagy and Anderson (1984) estimated an average of 3,000 words a year and an average of 300 to 400 words in the course of over a school year (Stahl, 1991). Such growth in vocabulary would have given the Grade 12 students an upper hand in the use of semantic analysis skills because of a more extensive lexicon available at their disposal. However, the current study is not intended to measure vocabulary knowledge. In semantic analysis, a certain degree of familiarity with common words is needed to establish better use of contextual clues available. Henceforth, a sufficient lexical development should be achieved for better use of the strategy (Ahmed, 2013).

Conversely, a significant difference in the level of semantic analysis skills of the students was observed when they are grouped according to track. To build a usable lexicon for semantic analysis, reading proficiency is highly needed. L2 readers are required to be familiar with as much as $95 \%$ of the given words in a text to arrive successfully at an inferred meaning of a target word. In this regard, the background of the learners per group is highly considerable. As preparation for college, the academic group is made up of learners who are more inclined to reading than the TVL learners. Studies have disclosed that students' inclined to higher education successfully made

Table 4A. Difference in the Semantic Analysis Skills by Grade Level

\begin{tabular}{|c|c|c|c|c|c|}
\hline \multirow[b]{2}{*}{ Variable } & \multicolumn{5}{|c|}{ Grade Level } \\
\hline & $\begin{array}{l}\text { Grade } \\
11\end{array}$ & $\begin{array}{l}\text { Grade } \\
12\end{array}$ & $\mathbf{t}$ & df & p \\
\hline Restatement & $\begin{array}{l}1.72 \\
(1.35)\end{array}$ & $\begin{array}{l}2.00 \\
(1.42)\end{array}$ & 1.909 & 357 & 0.057 \\
\hline Synonym & $\begin{array}{l}1.98 \\
(1.19)\end{array}$ & $\begin{array}{l}2.10 \\
(1.15)\end{array}$ & 1.020 & 357 & 0.308 \\
\hline Antonym & $\begin{array}{l}2.14 \\
(1.30)\end{array}$ & $\begin{array}{l}2.20 \\
(1.38)\end{array}$ & 0.392 & 357 & 0.695 \\
\hline Definition & $\begin{array}{l}2.15 \\
(1.10)\end{array}$ & $\begin{array}{l}2.31 \\
(1.16)\end{array}$ & 1.337 & 357 & 0.182 \\
\hline Semantic Analysis Skills & $\begin{array}{l}7.99 \\
(3.39)\end{array}$ & $\begin{array}{l}8.61 \\
(3.70)\end{array}$ & 1.660 & 357 & 0.098 \\
\hline
\end{tabular}

Note: *the difference in the means is significant when $\mathrm{p} \leq 0.05$ 
use of semantic analysis skills to infer meaning (Webb, 2008) and tend to use more varied vocabulary strategies than those who are vocational-oriented (Wen, 2006).

Similarly, a significant difference was noted in the level of semantic analysis skills of the students when they are grouped according to sex. However, there are no available studies that highlight specific semantic analysis as a whole and specifically its subcategories. An analysis may be done using the understanding of how males and females tend to differ in terms of linguistic competence.

Based on the semantic analysis skills of senior high school, if grouped according to sex, the females significantly outperformed the males. Instead of becoming an aid, there is a threat that contextual clues may become burdens because L2 readers are estimated to need to know as much as $95 \%$ of the words in context to successfully use them as clues ( $\mathrm{Na} \&$ Nation, 1985). Because it commonly pointed out that women are more linguistically successful than men $(\mathrm{Gu}, 2002)$ as indicated in girls exhibit better reading ability, reading frequency, and have a more positive attitude towards reading, a requirement of $95 \%$ known of the context may be easier complied by females than males.

Table 4B. Difference in the Semantic Analysis Skills by Track

\begin{tabular}{lllllc}
\hline Variable & $\begin{array}{l}\text { Track } \\
\text { Academic }\end{array}$ & TVL & t & df & p \\
& 2.42 & 1.48 & $6.622^{*}$ & 357 & 0.000 \\
\multirow{2}{*}{ Restatement } & $(1.41)$ & $(1.24)$ & & & \\
\hline \multirow{2}{*}{ Synonym } & 2.36 & $\begin{array}{l}1.82 \\
(1.09)\end{array}$ & $4.337^{*}$ & 357 & 0.000 \\
& $(1.23)$ & $(1.09)$ & & \\
\hline \multirow{2}{*}{ Antonym } & 2.74 & 1.80 & $6.869^{*}$ & 357 & 0.000 \\
& $(1.41)$ & $(1.16)$ & & & \\
\hline \multirow{2}{*}{ Definition } & 2.56 & 2.00 & $4.740^{*}$ & 357 & 0.000 \\
& $(1.21)$ & $(1.01)$ & & & \\
\hline \multirow{2}{*}{ Semantic Analysis Skills } & 10.08 & 7.10 & $8.495^{*}$ & 357 & 0.000 \\
& $(3.69)$ & $(2.91)$ & & & \\
\hline
\end{tabular}

Note: *the difference in the means is significant when $p \leq 0.05$

Table 4C. Difference in the Semantic Analysis Skills by Sex

\begin{tabular}{|c|c|c|c|c|c|}
\hline \multirow{2}{*}{ Variable } & \multicolumn{2}{|l|}{ Sex } & \multirow[t]{2}{*}{$\mathrm{t}$} & \multirow[t]{2}{*}{ df } & \multirow[t]{2}{*}{$p$} \\
\hline & Male & Female & & & \\
\hline \multirow{2}{*}{ Restatement } & 1.57 & 2.10 & $3.725^{*}$ & 357 & 0.000 \\
\hline & $(1.30)$ & $(1.42)$ & & & \\
\hline \multirow{2}{*}{ Synonym } & 1.94 & 2.12 & 1.481 & 357 & 0.140 \\
\hline & (1.11) & $(1.22)$ & & & \\
\hline \multirow{2}{*}{ Antonym } & 1.95 & 2.37 & $2.987^{*}$ & 357 & 0.003 \\
\hline & $(1.30)$ & $(1.35)$ & & & \\
\hline \multirow{2}{*}{ Definition } & 2.00 & 2.43 & $3.650 *$ & 357 & 0.000 \\
\hline & (1.13) & (1.09) & & & \\
\hline \multirow{2}{*}{ Semantic Analysis Skills } & 7.46 & 9.02 & $4.280^{*}$ & 357 & 0.000 \\
\hline & (3.34) & (3.56) & & & \\
\hline
\end{tabular}


Generally, the results supported the assertions of Constructivism that learning is a process of analysis of current knowledge to create a new meaningful interpretation (Taber, 2011). The respondents were able to tap on their existing skills to address the items required in the study. Although intervention in general needed, there is visible proof of the learners' foundations already present. In this study, the respondents demonstrated the use of past inputs to guess the possible meaning of newly encountered words. Furthermore, the use of schema was evident at how the respondents used prior knowledge to aid in determining the meaning of word parts and comprehending context.

\subsection{Conclusion}

The senior high school students exhibited limited background knowledge in recognizing word components that include prefix, suffix, and root word as their low performances showed. In general, they performed better in terms of using contextual clues rather than analyzing the structure. These findings revealed that although both skills have been given particular focus, the development of the learners' use for them is unequal.

Furthermore, the grade level of the respondents did not influence their morphemic and semantic analyses skills. Therefore, longer contact hours under formal education did not seem to affect the development of these skills, especially that these skills are not necessarily practiced. On the other hand, the results showed that academic track students used both morphemic and semantic analyses differently than did their TVL counterparts. It is observable that the choice of the students' focus on education serves as a motivation in learning and developing these skills compared to that of the TVL students. In addition, the males' and females' morphemic and semantic analyses skills are significantly different. The utilization of morphemic analysis as a skill is affected by one's sex, thus, revealing the statistical difference between males and females. Thus, it further provides a broader idea of how different male and female brains react to language.

Considering the competencies prescribed in the $\mathrm{K}-12$ Curriculum, it is conclusive that the build-up of the schema is observable; however, actual practice is limited or underdeveloped. To dig deeper into this perspective, scaffolding and constructivist application are seen to display observable effects, but retention of the skill may differ depending on the incidental or continuous practice.

\subsection{Recommandations}

From the findings and conclusions of this study, this research advances the following recommendations:

There is a need for strengthening of the morphemic and semantic analyses skills of students during their elementary and secondary education in preparation for senior high school. Senior high school teachers should continually integrate vocabulary in teaching English related subjects to give the opportunity for continual application of skills taught in earlier years. 
Furthermore, as seen in the results, there is a significant difference in the level of performance between the academic and TVL track and that of the males from the females. It revealed that females outperformed the males as well as the academic students performing better than their TVL counterparts. With this, it is apparent there is a need to consider sex and senior high school track preference of learners as early as junior high school to encourage development of morphemic and semantic analyses skills in particular and vocabulary in general. Currently, the K-12 Curriculum of the Department of Education does not fully consider these variables as factors in learning. The mainstream education of public schools in the Philippines do not directly apply differentiated instruction in terms of sex and future career preference of learners. As a matter of fact, the entire duration of the Junior High School, ideally, is focused on providing similar instruction and competencies to learners with little or no consideration of their future choice of tracks nor their sex. The programs of DepED are more focused on uniformed delivery and education for all. Basically, it is a "one size fits all" formula.

With the conclusions drawn from the current study as well as the findings of prior ones, the emphasis on the variables is strengthened. Hence, the Curriculum Implementation Division (CID) along with the Learning Resource and Management Database System (LRMDS) of the Division of Escalante City can consider developing specific programs and learning materials which address these findings especially in terms of specified instructional programs.

In addition, school heads may consider integrating vocabulary development as a separate elective to aid in developing reading comprehension for junior high school students. Instructional materials specialists/designers can further encourage the development of a proposed Vocabulary Building Module of Senior High School Students as a possible instructional aid in developing and strengthening the current morphemic and semantic analyses skills of the senior high school students.

Lastly, further studies on the fields of vocabulary is drastically needed to improve the current state of our learners.

\section{REFERENCES}

Ahmed, A. O. A. (2013). Lexis development: The importance of contextual clues. European Scientific Journal, ESJ, 9(35).

Akmajian, A., Farmer, A., Bickmore, L., Demers, R., \& Harnish, R. (2017). Linguistics: An introduction to Language and Communication. $7^{\text {th }}$ Edition. USA: Massachusetts Institute of Technology.

Bangs, K.E. \& Binder, K.S. (2016). Morphological awareness intervention: improving spelling, vocabulary, and reading comprehension for adult learners. J Res Pract Adult Lit Second Basic Educ. 2016 Spring;5(1):49-56. Retrieved from https://www.ncbi.nlm.nih. gov/ pubmed/27747145

Baumann, J.F., Font, G. Tereshinski, C. A., Olejnik, S. (2002). Teaching morphemic and contextual analysis to fifth-grade students. Reading Research Quarterly, Vol. 37, No. 2. Retrieved from https://ila.onlinelibrary.wiley.com/doi/abs/10.1598/RRQ.37.2.3 
Behlol, M. \&Kaini, M. M. (2011) Comparative effectiveness of contextual and structural method of teaching vocabulary. Canadian Center for Science and Education. Retrieved from https:// eric.ed.gov/?id=EJ1080442

Bogaards, P., \& Laufer, B. (2004). Introduction. In P. Bogaards \& B. Laufer (Eds.), Vocabulary in a second language (pp. vii-xiv). Amsterdam, The Netherlands: John Benjamins Publishing Company.

Boonkongsaen, N. (2013). Factors affecting vocabulary learning strategies: A synthesized study. Naresuan University Journal: Science and Technology (NUJST), 20(2), 45-53.

Brusnighan, S.M. (2015). The role of semantics in orthographic and phonological learning. (Dissertation submitted to Kent State University. Retrieved from https://etd.ohiolink. edu/!etd.send_file?accession=kent1429563014\&disposition=inline.

Buddingh, M. (2010). The effects of teaching roots and affixes on the vocabulary development of underperforming students (Doctoral dissertation)

Carlisle, J. F. (2010). Effects of instruction in morphological awareness on literacy achievement: An integrative review. Reading Research Quarterly, 45, 464-487.

Department of Education (2013; 2016). K to 12 Basic Education Curriculum. Retrieved from https://www.deped.gov.ph/k-to-12/about/k-to-12-basic-education-curriculum/

Diamond, L. \&Gultlohn , L. (2006). Teaching vocabulary. http: www.Readingrockets.org / article/9943/2013.

Easterbrook, R.M. (2013). The process of vocabulary learning: Vocabulary learning strategies and beliefs about language and language learning. PhD Thesis, University of Canberra. Retrieved from http://www.canberra.edu.au/researchrepository/file/ 3384527a-1649-4e50-b61f32a9979276e6/1/full_text.pdf

Flowerdew, L. (2015). Data-Driven learning and language learning theories. Mult Afford Lang Corpora Data-Driven Learn, 69, 15-36.

Greenwood, S. C., Flanigan, K. (2007). Overlapping vocabulary and comprehension: Context clues complement semantic gradients. The Reading Teacher. 61(3), 249- 254.

$\mathrm{Gu}, \mathrm{Y}$. (2002). Gender, academic major, and vocabulary learning strategies of Chinese EFL learners. RELC Journal, 33(1), 35-54.

Guo, Y., Roehrig, A. D., \& Williams, R. S. (2011). The relation of morphological awareness and syntactic awareness to adults' reading comprehension: Is vocabulary knowledge a mediating variable? Journal of Literacy Research, 43(2), 159-183.

Jose, G. R. (2015). Acquisition of vocabulary by Dint of Unique Strategies: Indispensible for Fostering English Language Skills. Journal on English Language Teaching, 5(2), 7-18. 
Karimi, M. N. (2012). Enhancing L2 students' listening transcription ability through a focus on morphological awareness. Journal of Psycholinguistic Research, 42(5), 451-459. doi:10.1007/ s10936-012-9227-1

Kieffer, M.J. \&Lesaux, N.K. (2007). Breaking words down to build meaning: Vocabulary, morphology, and reading comprehension in the urban classroom. The Reading Teacher, 61, 134-144.

Kile, C. A. (2013). Teaching morphemic contextual analysis skills (Master's thesis). Retrieved from http://csus-dspace.calstate.edu/

Laufer, B. \&Hulstijn, J. (2001). Incidental vocabulary acquisition in a second language: the construct of task-induced involvement, Applied Linguistics, Volume 22, Issue 1, March 2001, Pages 1-26, https://doi.org/10.1093/applin/22.1.1

Llach, M. P. A. \& Gallego, M. T. (2015). Vocabulary Knowledge Development and Gender Differences in a Second Language. Estudios de lingüísticainglesaaplicada (ELIA)

Luz, JM. (2007). A Nation of Nonreaders. Governance, i Report, Stories, Youth and Education. Retrieved from: https://pcij.org/stories/a-nation-of-nonreaders/

Marwan, A. (2017). ESP teaching challenges in an Indonesian vocational higher institution. The English Teacher, 12.

Masrai, A. \& Milton, J. (2012). The vocabulary knowledge of university students in Saudi. TESOL Arabia Perspectives, 19 (3):13-19.

McGregor, W.B. (2009). Linguistics: An introduction. USA \& U.K: Continuum International Publishing Group.

$\mathrm{Na}$, L., \& Nation, I. S. P. (1985). Factors affecting guessing vocabulary in context. RELC journal, 16(1), 33-42

Nagy, W., \& Anderson, R. (1984). The number of words in printed school English. Reading Research Quarterly, 19, 304-330. Retrieved from http://www.jstor.org/stable/747823? origin= JSTOR-pdf.

Nagy, W., Herman, P., \& Anderson, R. (1985). "Learning words from context". Reading Research Quarterly, Vol.85, pp.233-253.

Nagy, W., Anderson, R., \& Herman, P. A. (1987). Learning word meanings from context during normal reading. American Educational Research Journal, 24(2), 237-270

Oz, H. (2014). Morphological awareness and some implications for English language teaching. Procedia-Social and Behavioral Sciences, 136, 98-103

Royce Adams, W. \& Patterson, B. (2005). Developing reading versatility. $9^{\text {th }}$ Edition. USA: Thomson Wadsworth. 
Rumelhart, D.E. 1980. Schemata: The building blocks of cognition. In R. Spiro, B. Bruce and W. Brewer(eds.), Theoretical Issues in Reading Comprehension. Hillsdale, NJ: Lawrence Erlbaum Associates.

Shakouri, N., Sheikhy Behdani, R., \& Teimourtash, M. (2017). On the relationship between linguistic intelligence and recalling lexical items in SLA. International Journal of Research Studies in Education, Volume 6, Issue Number 4, October 2017. https://doi.org/10.5861/ ijrse.2016.1644

Stahl, S. A. (1991). Beyond the instrumental hypothesis: Some relationships between word meanings and comprehension. In P. J. Schwanenflugel (Ed.), The psychology of word meanings (pp. 157-185). Hillsdale, NJ: Erlbaum.

Taber, K. S. (2011). Guiding the practice of constructivist teaching. Teacher Development, 15(1), 117-122.

Varatharajoo, C., Asmawi, A., Rengasamy, S., Sukumaran, S. D., Sia Seng Lee, W. A., Raju, S., \& Ahmad, Z. (2014). The effect of morphemic analysis instruction on ESL secondary school students' vocabulary development.

Vygotsky, L. (1986). Thought and language. Cambridge, MA: The MIT Press.

Vygotsky, L. S. (1978). Mind in society: The development of higher psychological processes. Cambridge, MA: Harvard University Press.

Wang, Q. (2011). Lexical inferencing strategies for dealing with unknown words in reading-A contrastive study between Filipino graduate students and Chinese graduate students. Journal of Language Teaching and Research, 2(2), 302.

Wanpen, S., Sonkoontodb, K. \& Nonkukhetkhong, K.(2012). Technical vocabulary proficiencies and vocabulary learning strategies of engineering students. Procedia-Social and Behavioral Sciences 88 ( 2013 ) 312 - 320. doi: 10.1016/j.sbspro.2013.08.511

Webb, S. (2008). The effects of context on incidental vocabulary learning. Reading in a Foreign Language, 20(2), 232-245.

Wen DJ. Vocabulary learning strategies of academic-oriented and vocational-oriented students. Unpublished thesis NCCU Institutional repository; 2006.

Wilson, A. (2013). The Impact of Inferring Word Meaning: Context Clues. Greenwood, S. C., Flanigan, K. (2007). Overlapping vocabulary and comprehension: Context clues complement semantic gradients. The Reading Teacher. 61(3), 249- 254.

Zoghi, M., \& Malmeer, E. (2013). The Effect of Dynamic Assessment on EFL Learners' Intrinsic Motivation. Journal of Language Teaching \& Research, 4(3). 